\title{
PReS-FINAL-2011: Preliminary validation of a new hybrid measure of muscle strength for juvenile dermatomyositis
}

\author{
D Marafon ${ }^{1 *}$, A Consolaro ${ }^{1}$, C Ferrari ${ }^{1}$, S Dalprà ', A Madeo ${ }^{1}$, A Providenti', C Malattia ${ }^{1}$, N Ruperto ${ }^{1}$, A Civino ${ }^{2}$, \\ A Martini ${ }^{1}$, A Ravelli ${ }^{1}$
}

From 20th Pediatric Rheumatology European Society (PReS) Congress

Ljubljana, Slovenia. 25-29 September 2013

\section{Introduction}

Juvenile dermatomyositis (JDM) is a multisystem vasculopathic disease characterized by muscle inflammation that causes symmetrical muscle weakness. Assessment of muscle strength is, therefore, a fundamental component of the clinical evaluation of children with JDM. This assessment is traditionally made using the 8-muscle Manual Muscle Testing (MMT) and the Childhood Myositis Assessment Scale (CMAS). However, the MMT does not cover all muscles or muscle groups affected in JDM, namely abdominal muscles. Although the CMAS is more comprehensive than the MMT, it is lengthy and, therefore, may not be feasible in a busy clinical setting or when a physical therapist is not available.

\section{Objectives}

The study aim was to investigate the construct validity of a new hybrid measure of muscle strength, named hybrid MMT/CMAS (hmc), developed by merging the MMT with 3 items of the CMAS.

\section{Methods}

The hmc is composed of all 8 items of the MMT and the following items of the CMAS: 1) head lift; 2) sits-ups; 3 ) floor rise. Item 3 ) is recoded on 0 to 9 scale. The total score of the hmc ranges from 0 (worst) to 100 (normal). The hmc has been validated over two groups of patients: 1) 322 children with JDM enrolled in a multinational long-term outcome survey (Ravelli et al. AC\&R 2010;62:63-72); 2) 294 children with DMG included in a multinational study validation of the preliminary definition of clinical response led by PRINTO (Ruperto N. $A C \& R$ 2008). Validation procedures were conducted by comparing the correlation of the hmc, MMT and CMAS with other conventional measures of JDM activity, physical function and damage. Correlations were computed by means of the Spearman's correlation coefficient and were considered good, moderate, or poor when the $r_{s}$ was $>$ $0.7,0.4-0.7$, or $<0.4$, respectively. The ability to catch the change over time was assessed by calculating the standardized response mean (SRM) between 2 consecutive visits (the SRM was considered satisfying if $>0.80$ ).

\section{Results}

The Spearman's correlations of hmc, MMT and CMAS with other measures of disease activity and damage are presented in the table 1 .

\section{Conclusion}

We have developed a new hybrid measure of muscle strength in JDM, which is more comprehensive than the MMT and more feasible than the CMAS. Overall, the construct validity of the hmc was superior to that of the MMT and CMAS.

\section{Disclosure of interest}

None declared.

${ }^{1}$ Istituto Giannina Gaslini, Genova, Italy

Full list of author information is available at the end of the article 
Table 1

\begin{tabular}{|c|c|c|c|c|c|c|c|c|c|c|c|}
\hline & $\begin{array}{l}\text { MYOACT Glob } \\
\text { VAS }\end{array}$ & $\begin{array}{l}\text { Parent } \\
\text { Global }\end{array}$ & DAS & MITAX & $\begin{array}{l}\text { MYOACT Muscle } \\
\text { VAS }\end{array}$ & CK & CHAQ & $\begin{array}{l}\text { MDI Glob } \\
\text { VAS }\end{array}$ & $\begin{array}{l}\text { MDI Muscle } \\
\text { VAS }\end{array}$ & $\begin{array}{l}\text { MDI } \\
\text { Extent }\end{array}$ & $\begin{array}{l}\text { MDI } \\
\text { Severity }\end{array}$ \\
\hline $\mathrm{Hmc}$ & -0.54 & -0.35 & -0.58 & -0.47 & -0.68 & -0.23 & -0.64 & -0.46 & -0.52 & -0.47 & -0.44 \\
\hline MMT & -0.58 & -0.35 & -0.58 & -0.47 & -0.69 & -0.21 & -0.62 & -0.47 & -0.54 & -0.46 & -0.43 \\
\hline CMAS & -0.42 & -0.28 & -0.50 & -0.40 & -0.61 & -0.27 & -0.54 & -0.40 & -0.47 & -0.43 & -0.39 \\
\hline
\end{tabular}

The SRM HMC, MMT, CMAS was, respectively, 0.90, 0.80 and 0.89 .

\section{Authors' details}

${ }^{1}$ Istituto Giannina Gaslini, Genova, Italy. ${ }^{2}$ Azienda Ospedaliera Card. G. Panico,

Tricase (LE), Italy.

Published: 5 December 2013

doi:10.1186/1546-0096-11-S2-P24

Cite this article as: Marafon et al:: PReS-FINAL-2011: Preliminary

validation of a new hybrid measure of muscle strength for juvenile

dermatomyositis. Pediatric Rheumatology 2013 11(Suppl 2):P24.

Submit your next manuscript to BioMed Central and take full advantage of:

- Convenient online submission

- Thorough peer review

- No space constraints or color figure charges

- Immediate publication on acceptance

- Inclusion in PubMed, CAS, Scopus and Google Scholar

- Research which is freely available for redistribution

Submit your manuscript at www.biomedcentral.com/submit 